\title{
Ontology specific visual canvas generation to facilitate sense-making-an algorithmic approach
}

\author{
Kaneeka Vidanage, Noor Maizura Mohamad Noor, Rosmayati Mohemad, \\ Zuriana Abu Bakar \\ Faculty of Ocean Engineering Technology and Informatics, University Malaysia Terengganu, Terengganu, Malaysia
}

\begin{abstract}
Article Info
Article history:

Received Mar 22, 2021

Revised Aug 6, 2021

Accepted Sep 1, 2021

Keywords:

Domain-specialist

Ontologist

Sensemaking

Visualization canvas

ABSTRACT

Ontologies are domain-specific conceptualizations that are both human and machine-readable. Due to this remarkable attribute of ontologies, its applications are not limited to computing domains. Banking, medicine, agriculture, and law are a few of the non-computing domains, where ontologies are being used very effectively. When creating ontologies for non-computing domains, involvement of the non-computing domain specialists like bankers, lawyers, farmers become very vital. Hence, they are not semantic specialists, particularly designed visualization assistance is required for the ontology schema verifications and sense-making. Existing visualization methods are not fine-tuned for non-technical domain specialists and there are lots of complexities. In this research, a novel algorithm capable of generating domain specialists' friendlier visualization canvas has been explored. This proposed algorithm and the visualization canvas has been tested for three different domains and overall success of $85 \%$ has been yielded.
\end{abstract}

This is an open access article under the CC BY-SA license.

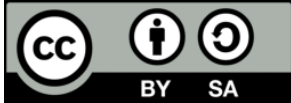

\section{Corresponding Author:}

Noor Maizura Mohamad Noor

Faculty of Ocean Engineering Technology and Informatics, Universiti Malaysia Terengganu

21030 Kuala Nerus, Terengganu, Malaysia

Email: maizura@umt.edu.my

\section{INTRODUCTION}

In the realm of ontological sensemaking, "visual compactness" is a major bottleneck and an unsolvable issue [1]. For the verification of the suggested conceptualizations, visualization is a must. The screen size, on the other hand, serves as a permanent barrier, limiting understanding of visualized contents for both ontologists and domain experts [2]. Ontology development is a collaborative effort including ontologists and domain experts. Domain specialists are often non-technical individuals such as farmers, attorneys, and medical professionals [3]. However, their participation is critical for the verification of the correctness of the ontology incrementally created by ontologists based on domain expert's expert inputs provided [4]. Many current visualization tools are designed with ontologists' task roles in mind. They are not fine-tuned to conform to the technical challenges that domain experts encounter [5]. However, it is well acknowledged that the logical use of appropriate technology can improve visualization clarity [6]. Consequently, the emphasis of this research is on developing a new algorithm capable of producing more user-friendly visualization canvases for domain experts in an ontology increment-specific manner, with no need for human configuration. 


\section{RELATED WORK}

2.1. Challenges

\subsubsection{Magnitude vs amount of information visualized}

The problem of visualizing the key elements of a conception without cognitively overwhelming stakeholders is yet unsolved [5]. Split attention, visual congestion, density, and occlusion are all troublesome properties that make it difficult for ontologists and domain experts to effectively make sense of ontologies. Figure 1 depicts a sound evidence for the above claim.

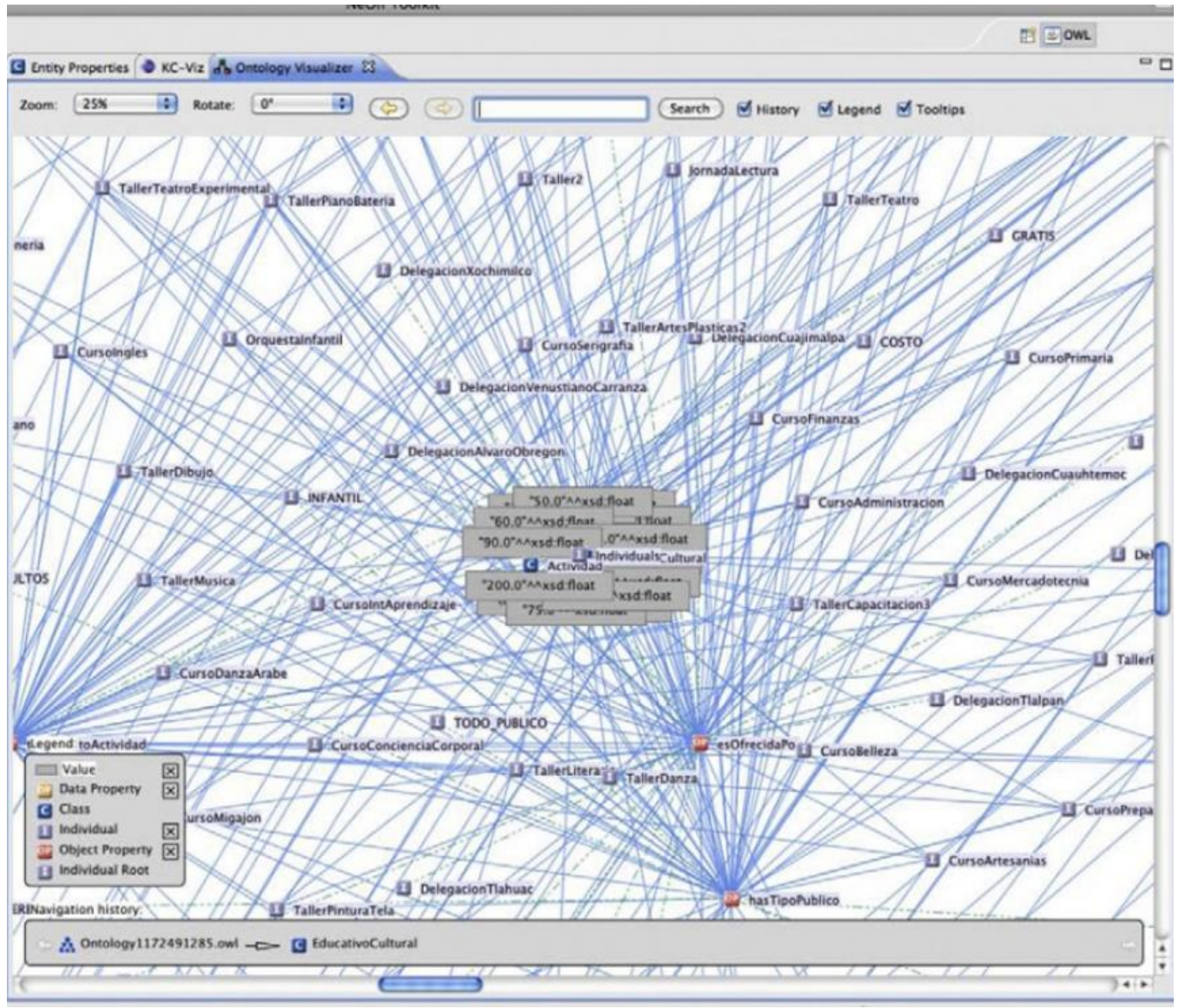

Figure 1. Visual canvas with occlusion and clutter

\subsubsection{Cognitive intricacy}

As ontological schemata grow more complex, visualizing canvases spontaneously acquire clotting and occlusion. As a result, this causes unnecessary horizontal and vertical movement for the user. Split attention problems exacerbate cognitive overload and information overload [5].

\subsubsection{D vs 3D}

Scientists have discovered that $3 \mathrm{D}$ representations complicate cognition more than 2D representations, triggering excessive mental burden [7], [8].

\subsubsection{Acquiring mastery and information loss}

Euler diagramming is a new approach to visualizing. However, it has been realized, that, it is very unproductive. Piercing theories, as well as complex mathematics, are needed to fully understand Euler Notation, which serves to make matters worse for domain experts [9]-[11]. 


\subsection{Existing visualization methods and algorithms}

\subsubsection{Graph-based methods}

Most people are acquainted with graph-based techniques. Clutter, occlusion, and information density all disrupt this technique. The presentation canvas is rendered too complicated when ontology schemata proliferate [12]-[14].

\subsubsection{Layout based methods}

Among the layout-based methods, force-directed, radial, inverted-radial, and circular layouts are being criticized for space waste, rotated textual representations, and loss of hierarchical structures [15], [16]. Because additional complexity triggers by these techniques complicates ontological sense-making for stakeholders. In low information densities, the tree-maps method offers certain positives [17]-[20]. However, in tree maps also, it will result in excessive clutter and occlusions with increased information density [21]-[23] as shown in Figure 2.

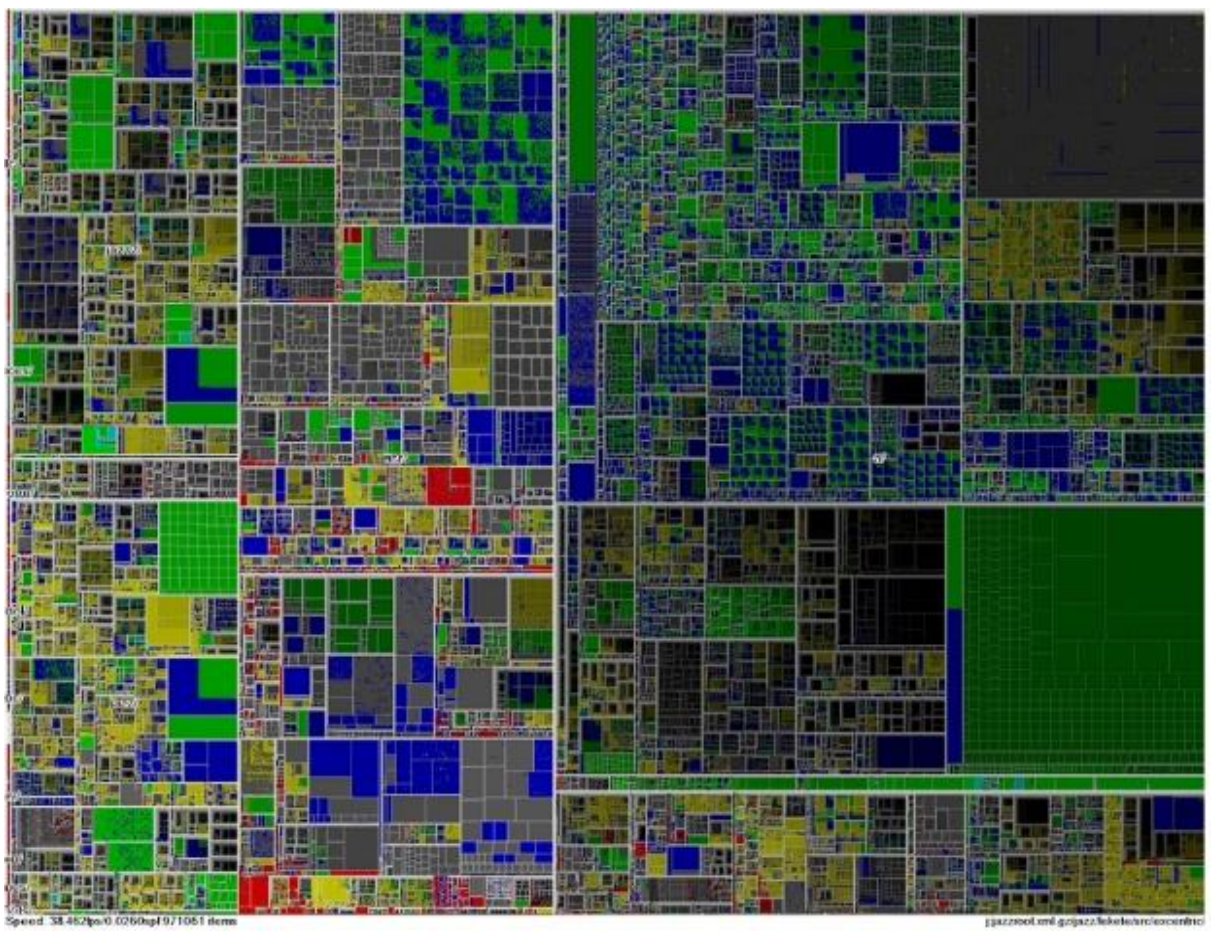

Figure 2. Occlusion and clutter resulting from extensive consolidation in a tree-map

\subsubsection{Euler diagraming method}

The learning curve involved with the euler diagramming method exacerbates the difficulty of ontological sense making. Additionally, information loss and a lack of a firm grasp on concepts such as data and object properties may be cited as shortcomings of this approach [9]-[11]. Table 1 summarizes the critical issues associated with existing visualization techniques. Meanwhile, Table 2 denotes a comparison of several prominent visualization tool and issues associated with those. Additionally, some of the prominent visualization algorithms are also reviewed and their deficiencies are summarized in Table 3.

Table 1. Comparison of existing visualization mechanisms

\begin{tabular}{cl}
\hline Visualization Category & \multicolumn{1}{c}{ Deficiency } \\
\hline Graph-based methods & $\begin{array}{l}\text { Clutter and occlusion, nodes and edges overlap on the presentation canvas, and all those } \\
\text { hinders understanding. Those will cause divided attention problems [12], [13]. }\end{array}$ \\
Layout based methods & $\begin{array}{l}\text { Excessive space waste, rotated text representation and loss of hierarchical structure, } \\
\text { information flooding and density, and excessive consolidations will add to the user's cognitive } \\
\text { burden. [15], [16] }\end{array}$ \\
Euler Diagraming methods & $\begin{array}{l}\text { Information loss, learning curve, mathematical representations associated makes } \\
\text { comprehension is going to be an additional overload to the end-user [9], [10] }\end{array}$ \\
\hline
\end{tabular}


Table 2. Visualization tool comparison

\begin{tabular}{|c|c|c|c|c|}
\hline Plugin/Tool & Category & Pros & Cons & Reflection \\
\hline Onto-Viz [24]] & Graph-based & $\begin{array}{l}\text { Hierarchical structuring is } \\
\text { preserved, and many users are } \\
\text { familiar with this technique. }\end{array}$ & $\begin{array}{l}\text { Outgrow quickly, resulting } \\
\text { in canvas occlusion. }\end{array}$ & $\begin{array}{l}\text { For domain experts, the } \\
\text { likelihood of developing a } \\
\text { cognitively sophisticated } \\
\text { visual representation is } \\
\text { higher. }\end{array}$ \\
\hline $\begin{array}{c}\text { OntoSphere } \\
{[25]}\end{array}$ & Graph-based & $\begin{array}{l}\text { A 2D hierarchical network and } \\
\text { a 3D spherical view are both } \\
\text { shown well. For each node, a } \\
\text { distinct color code is used. } \\
\text { Zooming is possible. }\end{array}$ & $\begin{array}{l}\text { Outgrows quickly, } \\
\text { resulting in canvas } \\
\text { occlusion. It is not feasible } \\
\text { to extract or withdraw } \\
\text { information. }\end{array}$ & $\begin{array}{l}\text { For domain experts, the } \\
\text { likelihood of developing a } \\
\text { cognitively sophisticated } \\
\text { visual representation is } \\
\text { higher. }\end{array}$ \\
\hline Jambalaya [26] & $\begin{array}{l}\text { Graph- } \\
\text { based and } \\
\text { Layout- } \\
\text { based }\end{array}$ & $\begin{array}{l}\text { Tree-map based technique, } \\
\text { provides a reasonable } \\
\text { resolution for the visualization } \\
\text { goals, at low information } \\
\text { densities. }\end{array}$ & $\begin{array}{l}\text { Quickly out grows the } \\
\text { canvas and making } \\
\text { excessive information } \\
\text { overloads. }\end{array}$ & $\begin{array}{c}\text { At the beginning of the } \\
\text { ontology increment, tree-map } \\
\text { mode is sufficient. However, } \\
\text { when the increment increases } \\
\text { in size, cognitive overload } \\
\text { will result, as seen in } \\
\text { Figure } 2 .\end{array}$ \\
\hline Swoop [28] & $\begin{array}{l}\text { Euler } \\
\text { diagram- } \\
\text { based }\end{array}$ & $\begin{array}{l}\text { In a circular perspective, } \\
\text { represents hierarchical } \\
\text { connections. The non- } \\
\text { overlapping of circles } \\
\text { represents disjointness. }\end{array}$ & $\begin{array}{l}\text { It is possible to lose } \\
\text { cardinality and property } \\
\text { information. It's easy to } \\
\text { outgrow and canvas, and } \\
\text { certain parts need } \\
\text { mathematics to understand. }\end{array}$ & $\begin{array}{l}\text { Information loss and steep } \\
\text { learning curve. }\end{array}$ \\
\hline
\end{tabular}

Table 3. Visualization algorithm comparison.

\begin{tabular}{|c|c|}
\hline Algorithm & Deficiency \\
\hline $\begin{array}{l}\text { Protein function prediction algorithm } \\
\qquad \text { (PFP) [29] }\end{array}$ & $\begin{array}{l}\text { It's a domain-dependent algorithm. PFP can work only for protein sequence matching } \\
\text { and representations. Because the algorithm is strongly linked with Gene ontology only. }\end{array}$ \\
\hline $\begin{array}{c}\text { Activation bit vector machine (ABVM) } \\
\text { Algorithm [30] }\end{array}$ & $\begin{array}{l}\text { It solely destroys the idea of the conceptual modelling of the domain. The notion of data } \\
\text { and object properties are also insignificant in this method. Further, this will not provide a } \\
\text { proper taxonomical schema for the ontology. Therefore, it is impossible to obtain the } \\
\text { traversal experience, to facilitate visual comprehension }\end{array}$ \\
\hline $\begin{array}{l}\text { Cognitive frame construction algorithm } \\
\text { [31] }\end{array}$ & $\begin{array}{l}\text { This algorithm is attempting to create an automated taxonomic structure for ontology. } \\
\text { Hence, it hinders the free will and creativity of the stakeholders. Also, the generated } \\
\text { taxonomical mappings could not be the most optimal ones. Because pure human } \\
\text { intervention is disturbed in this approach. Rather than a visualization algorithm, ideally, } \\
\text { this can be presented as an ontological construction algorithm. }\end{array}$ \\
\hline $\begin{array}{l}\text { Agreement marker visualization } \\
\text { technique [32] }\end{array}$ & $\begin{array}{l}\text { Though this technique is a visualization mechanism, it's mainly intended to visualize the } \\
\text { axiomatic similarities between a source and a target ontology. This technique is not } \\
\text { intended to facilitate the applied ontology construction process }\end{array}$ \\
\hline
\end{tabular}

\subsection{Reflection}

As already reviewed in the literature review section, almost most of the existing visualization techniques, tools and algorithms have a specified set of deficiencies. Additionally, none of them has concerned about fulfilling the requirement of domain specialist friendlier visualization necessity. Consequently, it can be argued as the research problem investigated in this research has not been effectively addressed via the existing resolutions.

\section{RESEARCH METHOD}

This research uses the design science research methodology (DSRM) [33]. DSRM is an excellent option for human-centered intervention research problems [34]-[36]. Thus, this research is also related to ontologists' and domain experts' sense-making difficulties. An improved version of DSRM as shown in Figure 3 was used in this research.

The first stage in the design science research process, as shown in Figure 3, is to literary justify the problem of concern. According to the items mentioned in the related work area, this phase has already been completed. The next stage is to come up with a possible solution. It was clear that the current processes, tools, and algorithms had flaws in terms of assisting domain experts in their role in ontological sense-making. Tables 1, 2, and 3 have previously been examined and logged with existing issues. As a result, the research 
aim for this study is to create a more user-friendly visualization canvas for domain specialists to successfully support their participation in collaborative ontology engineering objectives. After considerable brainstorming, the method shown below was developed to achieve the desired study goal. To improve understanding, the algorithm's process is divided into three stages, as shown in Figure 4.

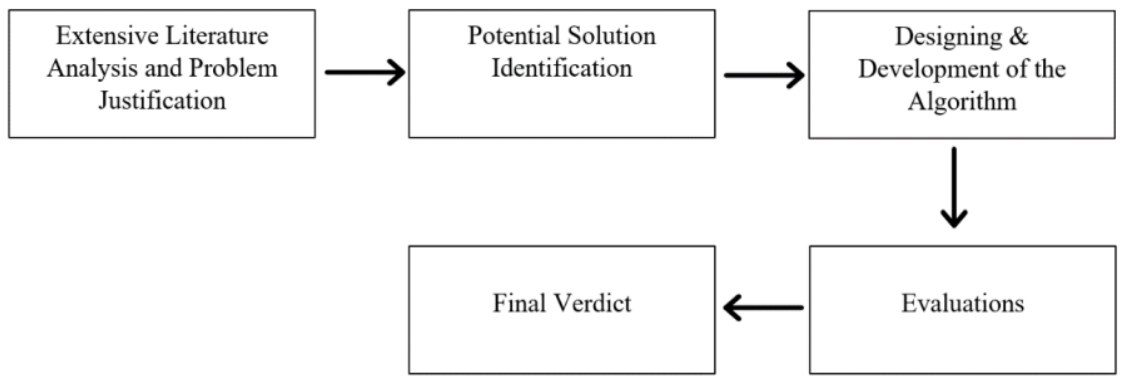

Figure 3. DSRM research workflow

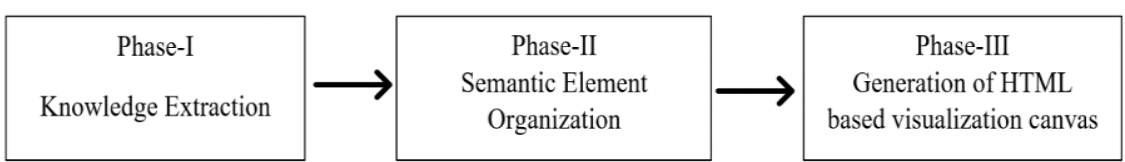

Figure 4. Executional workflow phases of the proposed algorithm

\subsection{Phase-I: Knowledge extraction}

The first phase of the algorithm is responsible for the extraction of the required knowledge elements from the ontology increment to be inspected and stowing them methodically inside the database.

Phase-I-[Knowledge Extraction]

Start

Upload RDF/OWL version of the ontology increment to be verbalized.

Check for the format as RDF or OWL.

Trigger format-specific knowledge extraction logic.

While [Until EOF==TRUE]

Extract class information

Extract data properties

Extract object properties

Extract class-specific individuals (if existing)

Stow them appropriately in different relations of the RDBMS. End While

Figure 5 depicts the code snippet associated with the practical implementation of the phase-I of the visualization canvas generation algorithm.

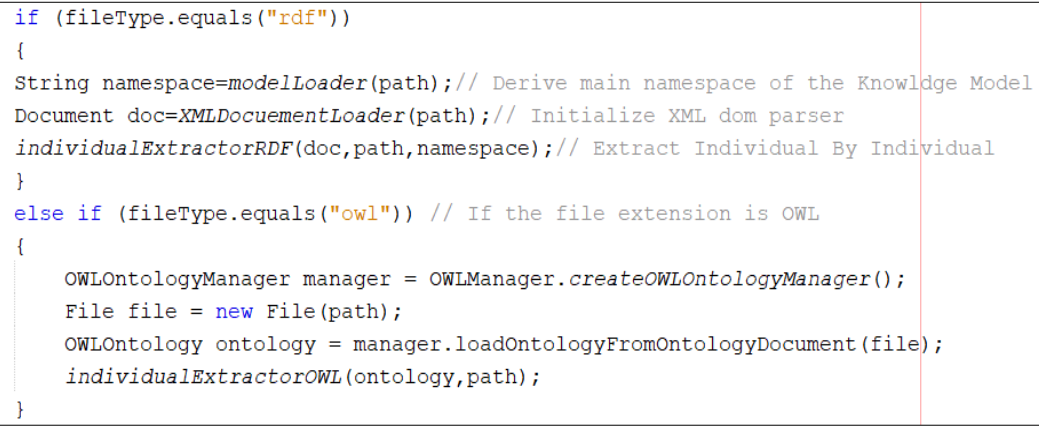

Figure 5. Knowledge extraction code snippet 


\subsection{Phase Phase-II: Semantic element organization}

The second phase of the ontology increments is very significant, as it does the main task of forming the domain specialist's friendlier visualization canvas.

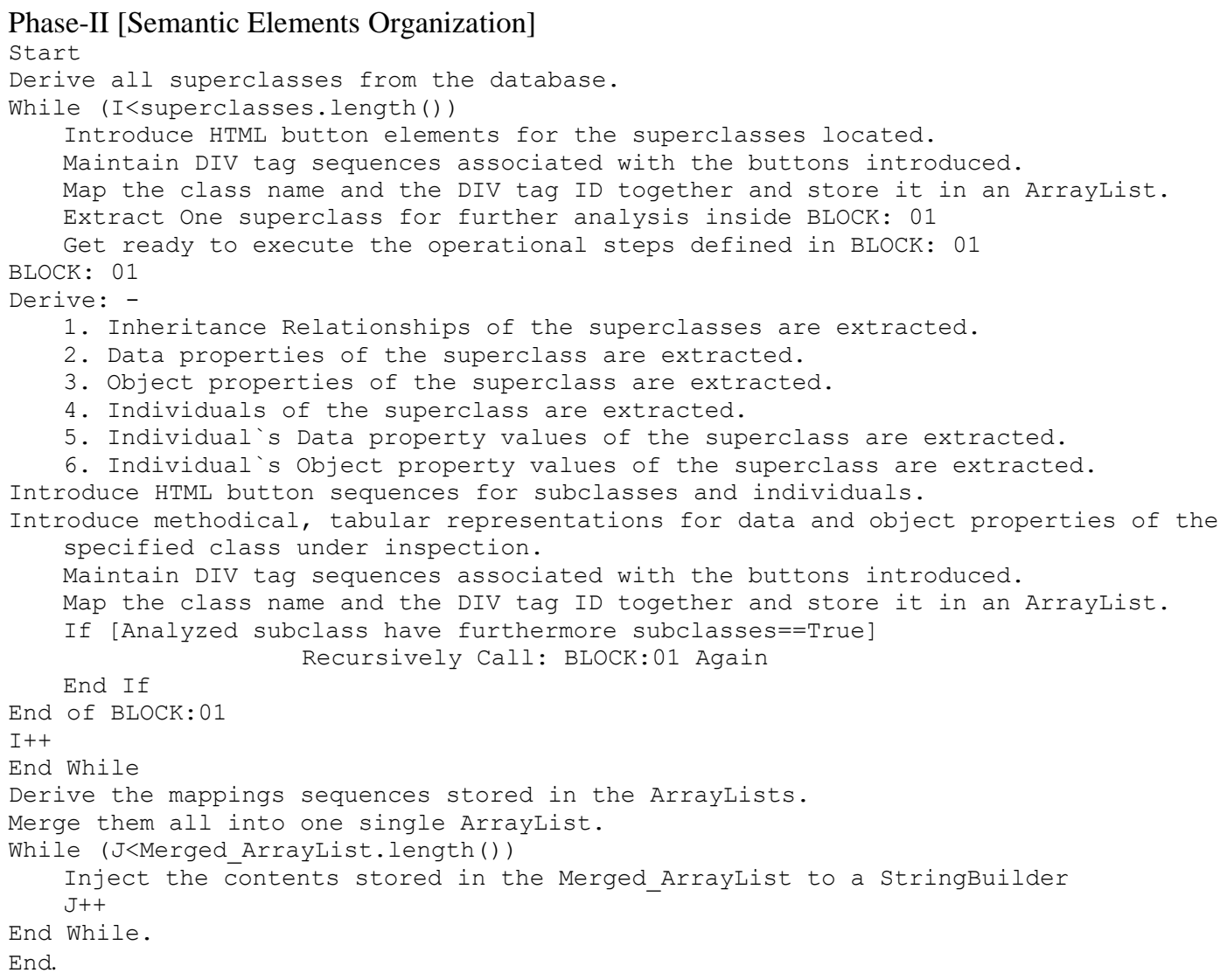

A portion of the associated code snippet responsible for div tag element sequence management is depicted in Figure 6.

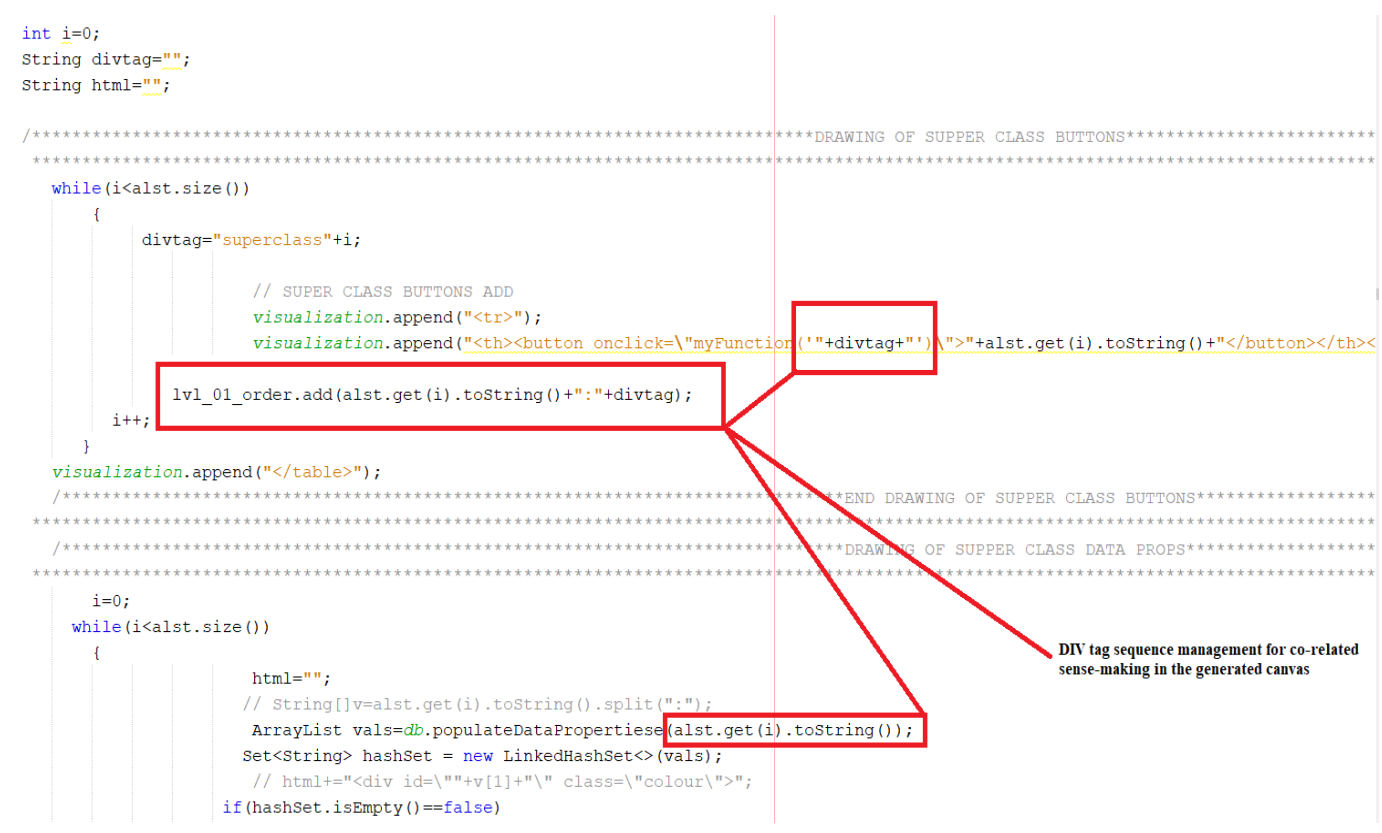

Figure 6. Semantic interactions mapping code snippet 


\subsection{Phase-III: Generation of the HTML based visualization canvas}

The third phase of the algorithm is responsible for the physical population of the HTML canvas. Figure 7 denotes the visualization canvas generated, whilst preserving the button sequences according to the semantic mappings residing inside the ontology increment to be inspected.
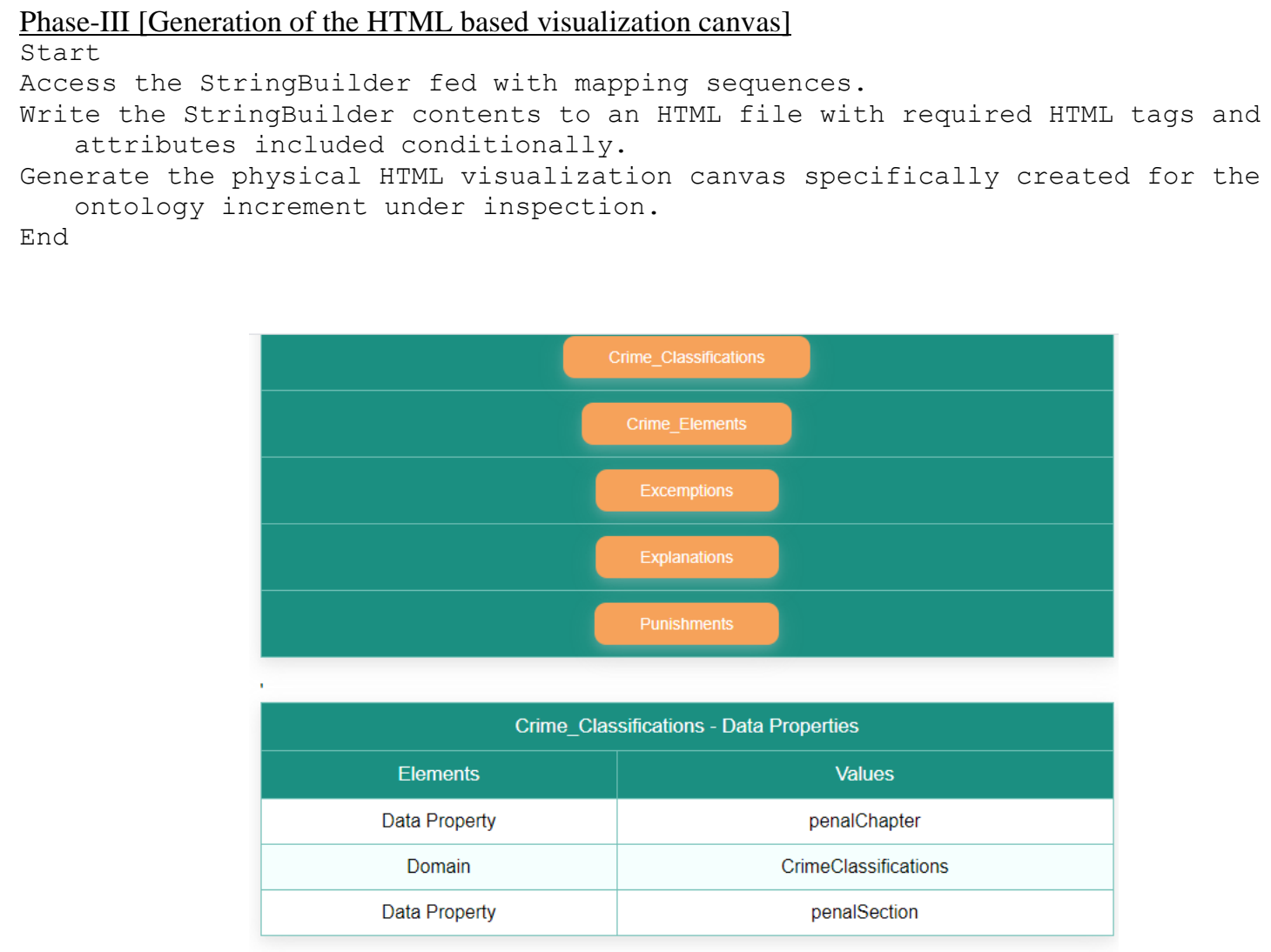

\begin{tabular}{|c|c|}
\hline \multicolumn{2}{|c|}{ Explanations - Object Properties } \\
\hline Elements & Values \\
\hline Object Property & describes \\
\hline Domain & Explanations \\
\hline Range & CrimeClassifications \\
\hline
\end{tabular}

Figure 7. Visualization canvas generated for crime ontology increment

\section{RESULTS AND DISCUSSION}

This proposed visualization canvas, and the algorithm has been tested across three different domains with the involvement of fifteen stakeholders. The utilized domains were COVID-19, criminal law, and Aquaculture. The operationalization step was first carried out. Several open-ended questions were compiled concerning the study's objectives. The process of operationalization is the mapping of the questionnaire questions with the study`s goal [37]. This will ensure that the answers gathered through the questionnaire's questions are highly relevant and consistent. Below is the list of open-ended questions mapped with the research objective to be assessed.

a. Have you been notified about the existing visualization mechanisms related to ontologies?

b. In contrast with those, do you identify any positive capabilities of the proposed structure?

c. Do you think it will facilitate the comprehension of the inspectors?

d. Can you elaborate, how it will facilitate the inspectors' comprehension?

e. What are the deficiencies you located in this proposed visualization canvas?

Both ontologists and domain specialists involved with this experiment were introduced to a specially generated synoptic video clip about the research conducted so far and explaining the workarounds 
of the proposed visualization canvas and the existing visualization strategies as part of the pre-warm-up setup. This phase acts as a retrospective and summarizes the important aspects of the research carried out by the stakeholders involved in the evaluation as well as resolves the doubts associated with the usage of visualization canvas also. This was done before the official commencement of the evaluation process since it will resolve all the unclear areas associated with the evaluation process. The five questions listed above were the key basis for governing the interview sessions with the fifteen stakeholders. All controlled interview sessions were video recorded to facilitate later analysis requirements. The recording was made by obtaining the prior approval and consent of all the participants involved and was used solely for study purposes and not for any other personal benefits.

During the thematic extraction process, all recorded interviews were transcribed into a textual format. Following that, the concerned research team iteratively analyzed the transcribed texts for many turns. All the information collected through the repetitive study was divided into a few general themes. At the start of the study, new themes emerged at a rapid rate; but, by gradually reaching up to the ninth transcription, there was a reduction in the emergence of the new themes, whilst the same themes repeated over and over. This trait was recognized as approaching the saturation state [38]. Theme extraction allowed the mainstream of the research's most significant traits to be identified. It was impossible to gather all relevant opinions solely based on numbers, limiting only to quantitative routines. Therefore, the qualitative phase, which was implemented through controlled interview sessions, allowed for the identification of significant and cognitively enriched user insights [38].

Following the outcomes derived from the qualitative phase of the evaluation, another set of closedended questions were created to elicit additional information on the identified themes. This enables us to focus our attention on particular themes with a numerical emphasis as well. Figure 8 shows the special rating grid which was used to extract stakeholder opinions in a quantitative flavor.

\begin{tabular}{|c|c|c|c|c|c|c|c|c|c|}
\hline 10 & 20 & 30 & 40 & 50 & 60 & 70 & 80 & 90 & 100 \\
\hline $\begin{array}{l}\text { Very } \\
\text { Poor }\end{array}$ & \multicolumn{4}{|c|}{ Fairly OK, but major flaws visible } & \multicolumn{3}{|c|}{$\begin{array}{l}\text { Good and acceptable - Only a few } \\
\text { minor revisions }\end{array}$} & \multicolumn{2}{|c|}{ Exceptional } \\
\hline
\end{tabular}

Figure 8. Quantitative rating grid

Following five questions were provided in a close-ended format and requested to rate the opinions for the quantitative scrutiny requirements.

a. Proposed visualization canvas restricts clutter and occlusion.

b. Proposed visualization canvas represents information in a layered architecture reducing information overload

c. Proposed visualization canvas restricts split attention issues.

d. Proposed visualization canvas provides hierarchical traversal experience assured with drill-down exploration abilities

e. How would you rate the visualization assistance provided by the tool support?

The following Table 4 summarizes the averaged response scores derived via fifteen domain specialists belonging to three different domains. Meanwhile, a summarized collection of the qualitative interpretations gathered through the controlled interview session were depicted in Table 5.

Table 4. Averaged quantitative response scores for three different domains for visualization canvas

\begin{tabular}{cc}
\hline Domain & Score \\
\hline Criminal Law & $88 \%$ \\
Covid-19 & $85 \%$ \\
Aquaculture & $83 \%$ \\
Averaged & $85 \%$ \\
\hline
\end{tabular}

Table 5. Refined qualitative opinions gathered via controlled interviews for visualization canvas Summary of Qualitative opinions from controlled interviews

1. Greatly controls occlusion and visual clutter.

2. Reduces split attention problems, by displaying related information in one place with proper packaging.

3. Layered-information representation, prevents overloading of information.

4. Hierarchical traversal experience with drill-down facilities for coherent information inquiry

5. Domain specialist friendlier visualization canvas. 
The iterative framework was used to focus on the research objective accomplishment as the final step of the evaluation process. The iterative framework [39] is a well-established framework for logically evaluating the efficacy of achieving research objectives. The iterative framework's operation is regulated by three separate but interrelated questions. For each section in place, reflective evidence must be presented. Table 6 summarizes the discussion surrounding the iterative framework measures.

The entire evaluation workflow utilized for this research is visible in Figure 9. This is a triangulated evaluation workflow newly introduced, considering both quantitative and qualitative facets associated with a human-centered evaluation setup. The entire evaluation workflow utilized for this research is visible in Figure 9. This is a triangulated evaluation workflow newly introduced, considering both quantitative and qualitative facets associated with a human-centered evaluation setup. According to the experiments conducted in three different domains with the involvement of fifteen stakeholders an average acceptance of $85 \%$ has been yielded. The ontologies designed are as depicted in Figures 10 to 12.

Table 6. Dialectics related with Iterative framework for this research

\begin{tabular}{|c|c|}
\hline Steps in Iterative Framework & Reflective Evidence \\
\hline $01 \rightarrow$ What are the data telling me? & $\begin{array}{l}\text { Quantitative Metrics-Multiple domain-specific quantitative opinion } \\
\text { scores were utilized to validate the efficacy of the built } \\
\text { visualization prototype and its operational effectiveness, as seen in } \\
\text { Table 5. It had yielded satisfactory results. } \\
\text { Qualitative Assessment-Empirical evaluation of the visualization } \\
\text { prototype was carried out with the participation of stakeholders } \\
\text { who contributed to the ontology increment constructions. In terms } \\
\text { of the results returned, precision, usability, "technical assistance } \\
\text { given", were important facets recognized. The stakeholders' } \\
\text { reflective opinion themes were also logged, as seen in Table } 6 \text {. } \\
\text { As a result of the overall study, both the quantitative and } \\
\text { qualitative experimental phases (triangulated evaluation strategy) } \\
\text { have produced satisfactory results. }\end{array}$ \\
\hline $02 \rightarrow$ What do I want to know? & $\begin{array}{l}\text { The overall operational efficacy of the visualization algorithm and } \\
\text { canvas developed to facilitate the role of the domain specialists } \\
\text { ontological sense-making }\end{array}$ \\
\hline $\begin{array}{l}03 \rightarrow \text { Is there a dialectical relationship between step } 01 \\
\text { and } 02 \text { ? }\end{array}$ & $\begin{array}{l}\text { The visualization prototype was exposed to several ontology } \\
\text { increments in three distinct domains during the quantitative } \\
\text { process of the evaluation. Quantitative matrices were measured in } \\
\text { all of these tests to assess the overall effectiveness of the } \\
\text { visualization prototype, and as per the results derived and logged } \\
\text { in Table } 4 \text {, it was clear that the overall operation was a success. } \\
\text { Stakeholder views were thematically analyzed during the } \\
\text { qualitative evaluation process, and the distilled results were } \\
\text { tabulated in Table } 5 \text {. } \\
\text { Both quantitative and qualitative evaluation phases were } \\
\text { completed, and the results were positive. } \\
\text { As a result, based on the iterative framework rationale, it can be } \\
\text { concluded that there is a positive and satisfactory relation between } \\
\text { steps } 01 \text { and } 02 \text {, reflecting the overall efficacy of the visualization } \\
\text { canvas/algorithm designed in this study. }\end{array}$ \\
\hline
\end{tabular}

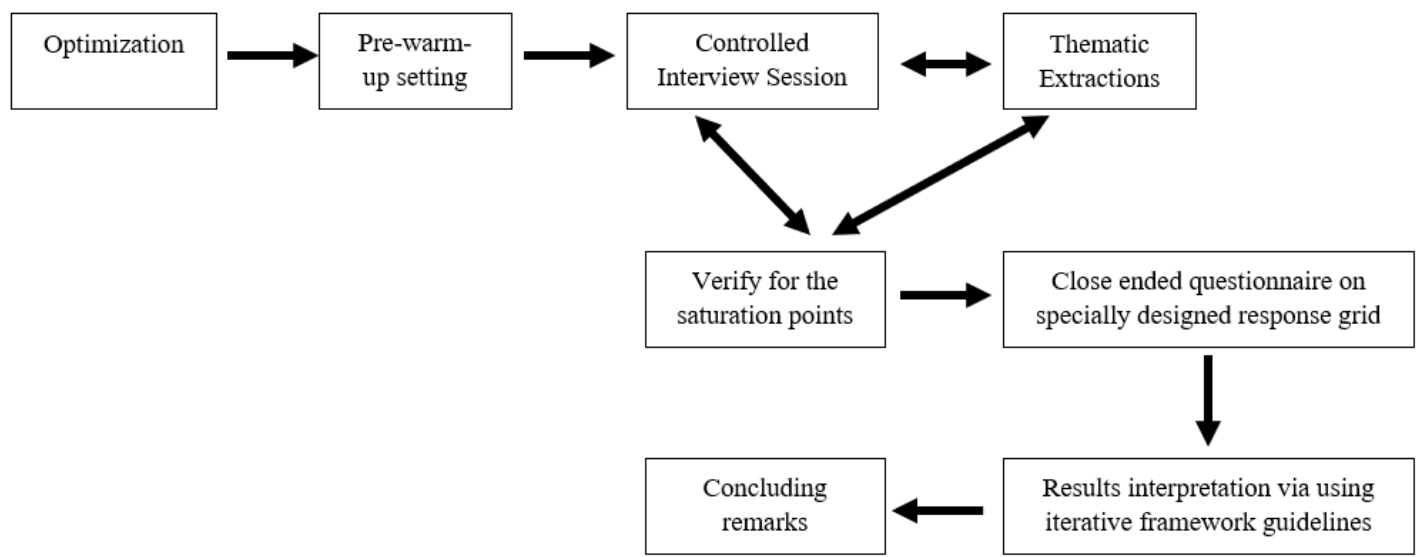

Figure 9. Entire evaluation flow 


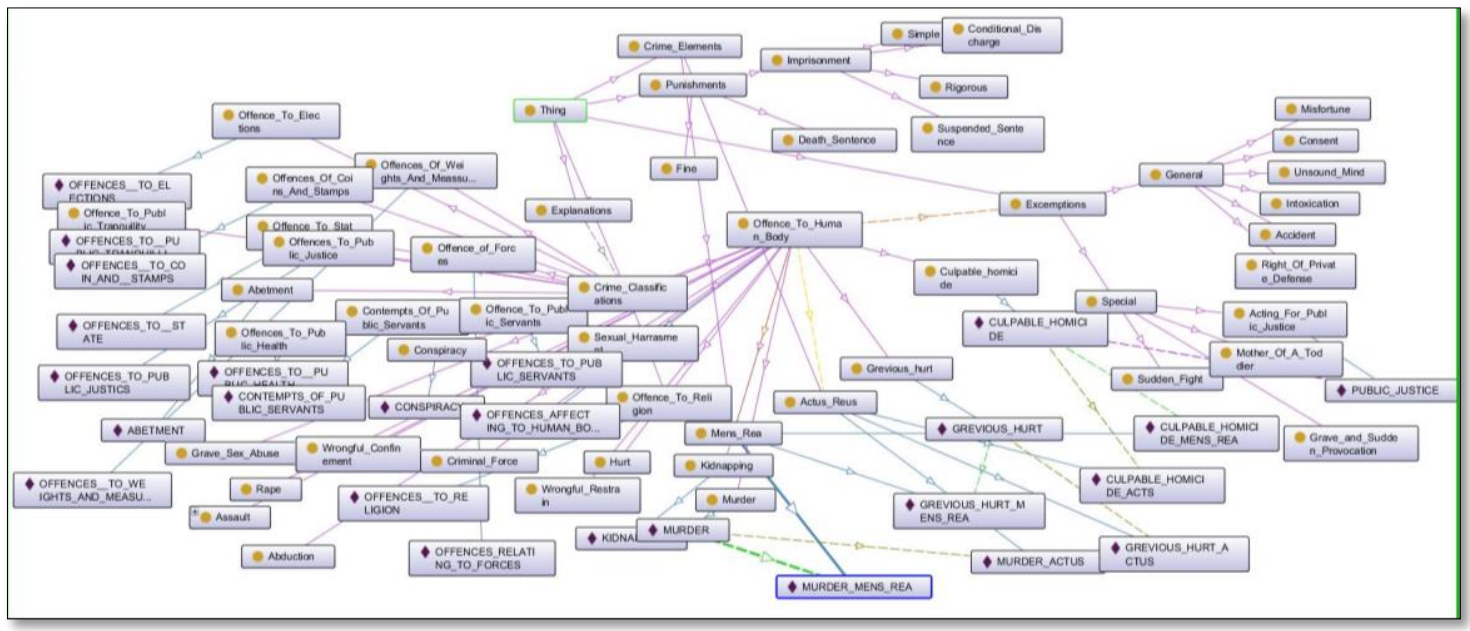

Figure 10. Criminal law ontology snapshot

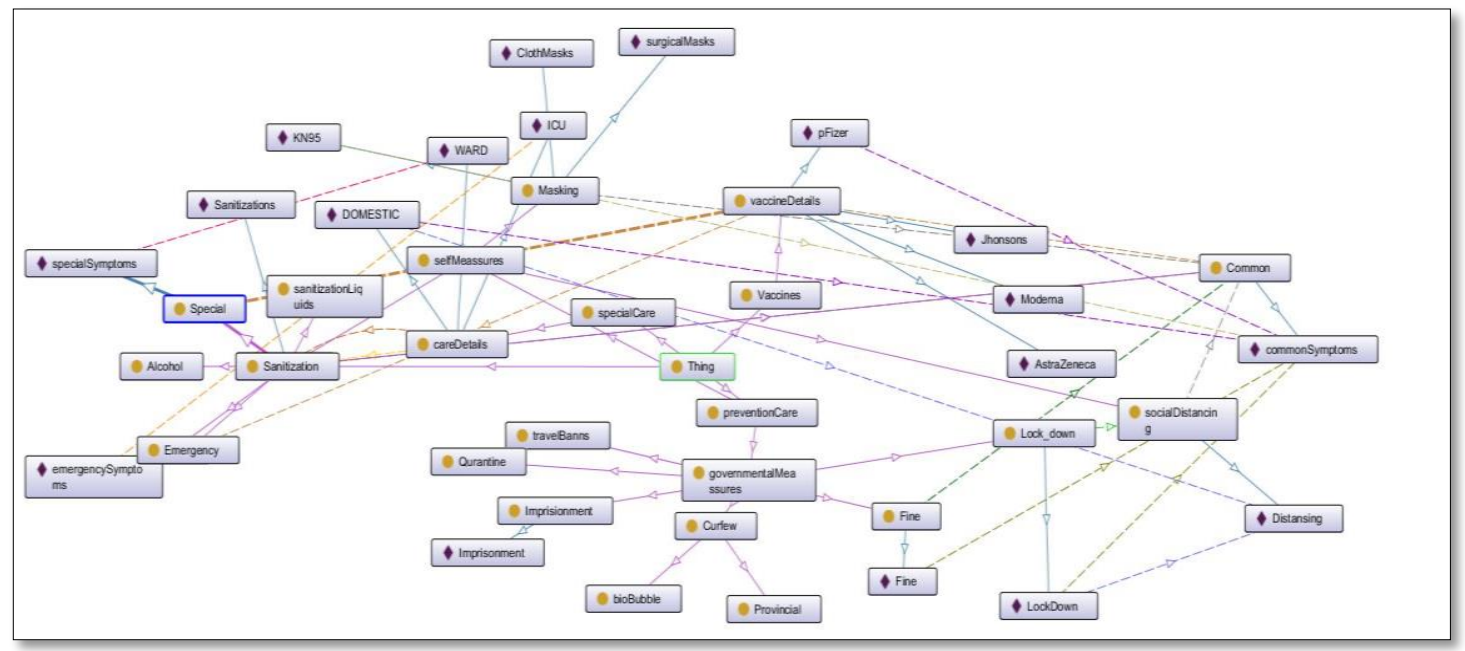

Figure 11. COVID-19 ontology snapshot

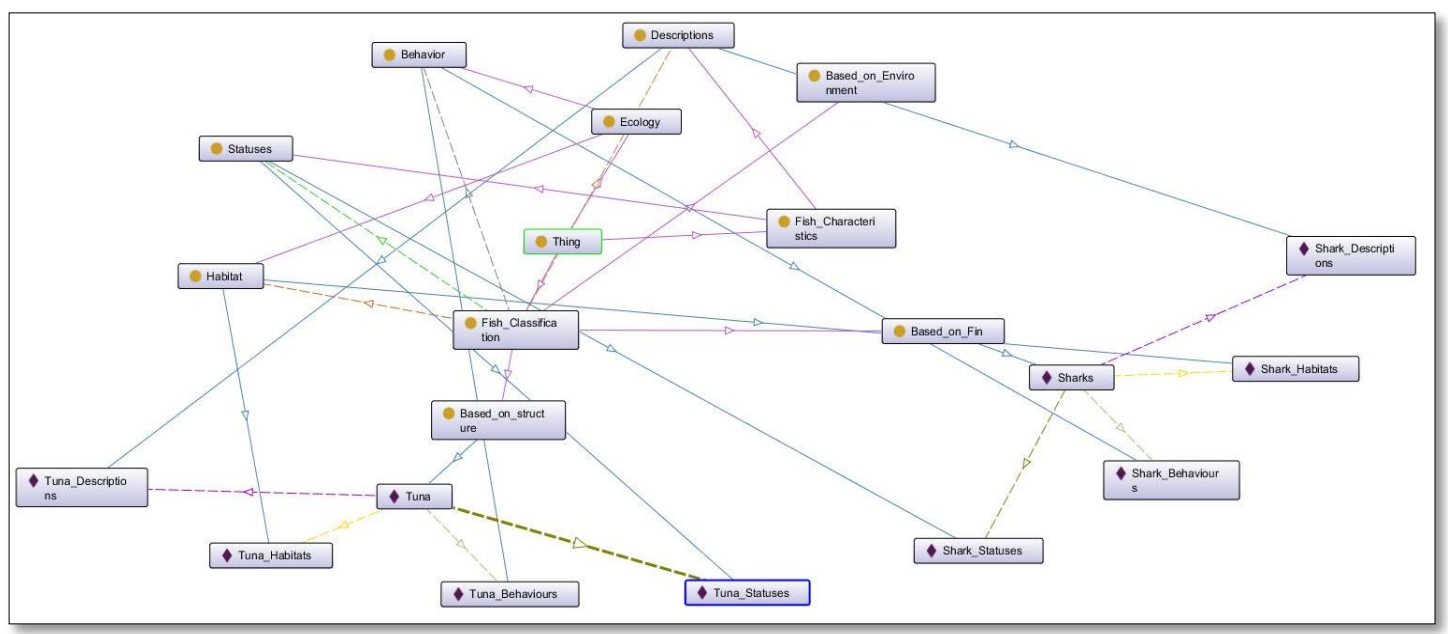

Figure 12. Fisheries ontology snapshot 


\section{CONCLUSION}

Domain specialists involvement in the ontological sense-making is very vital. Hence, they are specialists in respective domains, conceptual glitches can be located promptly. It will facilitate the role of the ontologists as well, by providing a strong platform for accurate conceptualizations. Existing visualization tools like Protégé, brid are too complex for non-technical domain specialists, as of their occlusion, cluttering and split attention problems. This research proposed a novel visualization canvas generation algorithm, which can: i) package semantic elements in a sensible sequence; ii) on-demand information representation prevents cognitive overloading; iii) cognitively enriched taxonomical traversal via pressing on the required hypertext markup language (HTML) buttons generated in the canvas; and iv) greatly controls extensive scrolling whilst reducing the split attention through drill-downed cohesive packaging of the semantic elements.

Therefore, this canvas reduces the technical grasp required for the non-technical domain specialists whilst providing a logically sound sense-making platform for ontological sense-making. This can be considered as a significant contribution to the niche of collaborative ontology engineering. In future, it's decided to improve the tool support further to facilitate the role of domain specialists in collaborative ontology engineering

\section{REFERENCES}

[1] L. Merino, E. Kozlova, O. Nierstrasz, and D. Weiskopf, "VISON: an ontology-based approach for software visualization tool discoverability," in 2019 Working Conference on Software Visualization (VISSOFT), Sep. 2019, pp. 45-55, doi: 10.1109/VISSOFT.2019.00014.

[2] S. Park, S. Kim, and Y. Ha, "Scalable visualization for DBpedia ontology analysis using Hadoop," Software: Practice and Experience, vol. 45, no. 8, pp. 1103-1114, Aug. 2015, doi: 10.1002/spe.2310.

[3] E. Motta, S. Peroni, J. M. Gómez-Pérez, M. D’Aquin, and N. Li, "Visualizing and navigating ontologies with KC-Viz," in Ontology Engineering in a Networked World, Berlin, Heidelberg: Springer Berlin Heidelberg, 2012, pp. 343-362.

[4] I. C. S. Silva, G. Santucci, and C. M. D. S. Freitas, "Visualization and analysis of schema and instances of ontologies for improving user tasks and knowledge discovery," Journal of Computer Languages, vol. 51, pp. 28-47, Apr. 2019, doi: 10.1016/j.cola.2019.01.004.

[5] S. Carpendale et al., "Ontologies in biological data visualization," IEEE Computer Graphics and Applications, vol. 34, no. 2, pp. 8-15, Mar. 2014, doi: 10.1109/MCG.2014.33.

[6] A. Anikin, D. Litovkin, M. Kultsova, E. Sarkisova, and T. Petrova, "Ontology visualization: approaches and software tools for visual representation of large ontologies in learning," in Communications in Computer and Information Science, Springer International Publishing, 2017, pp. 133-149.

[7] A. Saghafi, "Visualizing ontologies-a literature survey," Springer International Publishing, 2016, pp. $204-221$.

[8] "15. Multimodal academic argument in data visualization," in Data Visualization in Society, Amsterdam University Press, 2020, pp. 239-256.

[9] A. Baimagambetov, G. Stapleton, A. Blake, and J. Howse, "Evaluating visualizations of sets and networks that use euler diagrams and graphs," in Diagrammatic Representation and Inference, Springer International Publishing, 2020, pp. 323-331.

[10] G. Stapleton, Leishi Zhang, J. Howse, and P. Rodgers, "Drawing euler diagrams with circles: The theory of piercings," IEEE Transactions on Visualization and Computer Graphics, vol. 17, no. 7, pp. 1020-1032, Jul. 2011, doi: 10.1109/TVCG.2010.119.

[11] P. Rodgers, G. Stapleton, J. Flower, and J. Howse, "Drawing area-proportional euler diagrams representing up to three sets," IEEE Transactions on Visualization and Computer Graphics, vol. 20, no. 1, pp. 1-1, Jan. 2014, doi: 10.1109/TVCG.2013.104

[12] J. U. Kidav, N. M. Siva Mangai, and M. P. Pillai, "Design of AWC core using DCD iterations for MVDR beamformer," Microprocessors and Microsystems, vol. 73, no. 1, Art. no. 102969, Mar. 2020, doi: 10.1016/j.micpro.2019.102969.

[13] V. Wiens, S. Lohmann, and S. Auer, "Semantic zooming for ontology graph visualizations," in Proceedings of the Knowledge Capture Conference, Dec. 2017, pp. 1-8, doi: 10.1145/3148011.3148015.

[14] N. Peppes, T. Alexakis, E. Adamopoulou, K. Remoundou, and K. Demestichas, "A semantic engine and an ontology visualization tool for advanced crime analysis," Procedia Computer Science, vol. 176, pp. 1829-1838, 2020, doi: 10.1016/j.procs.2020.09.222.

[15] M. Florrence Joseph and R. Lourdusamy, "Feature analysis of ontology visualization methods and tools," Computer Science and Information Technologies, vol. 1, no. 2, pp. 61-77, Jul. 2020, doi: 10.11591/csit.v1i2.p61-77.

[16] Z. Liu, F. Bai, and Z. Tan, "Variable observation window length blind equalization detector for underwater acoustic communication," EURASIP Journal on Wireless Communications and Networking, vol. 2020, no. 1, Dec. 2020, Art. no. 143, doi: 10.1186/s13638-020-01755-9.

[17] X. Zhang, S. Chandrasegaran, and K.-L. Ma, "ConceptScope: organizing and visualizing knowledge in documents based on domain ontology," in Proceedings of the 2021 CHI Conference on Human Factors in Computing Systems, May 2021, pp. 1-13, doi: 10.1145/3411764.3445396.

[18] F. Supek, M. Bošnjak, N. Škunca, and T. Šmuc, "REVIGO summarizes and visualizes long lists of gene ontology terms," PLoS ONE, vol. 6, no. 7, Jul. 2011, Art. no. e21800, doi: 10.1371/journal.pone.0021800.

[19] I. Baimuratov, T. Nguyen, R. Golchin, and D. Mouromtsev, "Developing non-empirical metrics and tools for ontology visualizations evaluation and comparing," Scientific Visualization, vol. 12, no. 4, pp. 71-84, 2020, doi: 10.26583/sv.12.4.07.

[20] C. Li, G. Baciu, Y. Wang, and X. Zhang, "Fast content-aware resizing of multi-layer information visualization via adaptive triangulation," Journal of Visual Languages and Computing, vol. 45, pp. 61-73, Apr. 2018, doi: 10.1016/j.jvlc.2017.03.004.

[21] M. A. Yalçın, N. Elmqvist, and B. Bederson, "Raising the Bars: evaluating treemaps vs. wrapped bars for dense visualization of sorted numeric data," 2017.

[22] D. Litovkin, A. Anikin, and M. Kultsova, "Semantic zooming approach to semantic link network visualization," Springer International Publishing, 2019, pp. 81-95.

[23] D. Herr, Q. Han, S. Lohmann, and T. Ertl, "Hierarchy-based projection of high-dimensional labeled data to reduce visual clutter," Computers and Graphics, vol. 62, pp. 28-40, Feb. 2017, doi: 10.1016/j.cag.2016.12.004. 
[24] M. A. Musen, “The protégé project,” AI Matters, vol. 1, no. 4, pp. 4-12, Jun. 2015, doi: 10.1145/2757001.2757003.

[25] D. Shachnev and Lomosov, "Web ontology editor: architecture and applications," Lomonosov Moscow State University, 2017.

[26] M. Annamalai and Hamid Reza Mohseni, "Jambalaya: The closest visualisation fit for the protégé ontology conceptualrelationship tracer," in 2010 International Conference on Science and Social Research (CSSR 2010), Dec. 2010, pp. 201-206, doi: 10.1109/CSSR.2010.5773767.

[27] W. Hop, S. de Ridder, F. Frasincar, and F. Hogenboom, "Using Hierarchical Edge Bundles to visualize complex ontologies in GLOW," in Proceedings of the 27th Annual ACM Symposium on Applied Computing-SAC '12, 2012, pp. 304-311, doi: $10.1145 / 2245276.2245338$.

[28] S. K. Malik and S. A. M. Rizvi, “A group housing society ontology in Swoop 2.3 Beta 4 and Protege 3.4.4,” International Journal of Autonomic Computing, vol. 2, no. 1, pp. 21-38, 2014, doi: 10.1504/IJAC.2014.059111.

[29] Rejwana Haque, "Protein function prediction from genome sequence based on PFP algorithm," International Journal of Engineering Research and, vol. V6, no. 11, Nov. 2017, doi: 10.17577/IJERTV6IS110190.

[30] H. R. Schmidtke, "Logical rotation with the activation bit vector machine," Procedia Computer Science, vol. 169, pp. 568-577, 2020, doi: 10.1016/j.procs.2020.02.208

[31] P. Lomov and M. Shishaev, "Visualization of ontologies on the basis of cognitive frames for knowledge transmission," in Frontiers in Artificial Intelligence and Applications, pp. 283-290, 2021.

[32] I. F. Cruz, F. P. Antonelli, and C. Stroe, "AgreementMaker," Proceedings of the VLDB Endowment, vol. 2, no. 2, pp. 1586-1589, Aug. 2009, doi: 10.14778/1687553.1687598.

[33] J. Holopainen, O. Mattila, E. Pöyry, and P. Parvinen, "Applying design science research methodology in the development of virtual reality forest management services," Forest Policy and Economics, vol. 116, Art. no. 102190, Jul. 2020, doi: 10.1016/j.forpol.2020.102190.

[34] I.-C. Lin and W.-H. Hung, "Establishment of biometric verification system based on design science research methodology and sensing system for smart border control," Sensors and Materials, vol. 33, no. 6, Art. no. 1897, Jun. 2021, doi: 10.18494/SAM.2021.3267.

[35] J. Gregório, L. Reis, M. Peyroteo, M. Maia, M. Mira da Silva, and L. V. Lapão, "The role of design science research methodology in developing pharmacy eHealth services," Research in Social and Administrative Pharmacy, vol. 17, no. 12, pp. 2089-2096, Dec. 2021, doi: 10.1016/j.sapharm.2021.05.016.

[36] H.-Y. Kao, M.-C. Yu, M. Masud, W.-H. Wu, L.-J. Chen, and Y.-C. J. Wu, "Design and evaluation of hospital-based business intelligence system (HBIS): A foundation for design science research methodology," Computers in Human Behavior, vol. 62, pp. 495-505, Sep. 2016, doi: 10.1016/j.chb.2016.04.021.

[37] L. N. Jespersen, S. I. Michelsen, B. E. Holstein, T. Tjørnhøj-Thomsen, and P. Due, "Conceptualization, operationalization, and content validity of the EQOL-questionnaire measuring quality of life and participation for persons with disabilities," Health and Quality of Life Outcomes, vol. 16, no. 1, Art. no. 199, Dec. 2018, doi: 10.1186/s12955-018-1024-6.

[38] L. S. Nowell, J. M. Norris, D. E. White, and N. J. Moules, "Thematic analysis," International Journal of Qualitative Methods, vol. 16, no. 1, Dec. 2017, doi: 10.1177/1609406917733847.

[39] P. Srivastava and N. Hopwood, "Reflection/commentary on a past article: 'A practical iterative framework for qualitative data analysis," International Journal of Qualitative Methods, vol. 17, no. 1, Dec. 2018, doi: 10.1177/1609406918788204.

\section{BIOGRAPHIES OF AUTHORS}
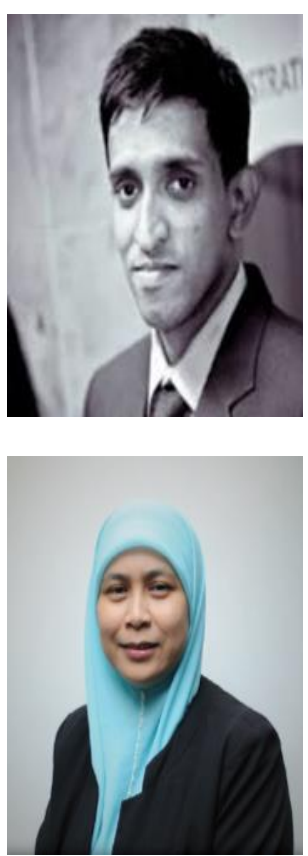

Kaneeka Vidanage (D) SC $\mathrm{SC}$ is a PhD level researcher affiliated to University Malaysia Terengganu. Kaneeka holds a M.Phil. in semantic web and ontology-based intelligence from University of Colombo, Master's in computer science from University of Colombo and BSc in Management Information Systems from National University or Ireland. He has already authors close to 30 publications in the domain of data science, artificial intelligence, and ontological modelling. He can be contacted at email: kaneeka.online@gmail.com.

Noor Maizura Mohamad Noor (iD) SC P is currently a professor at Faculty of Ocean Engineering Technology and Informatics, Universiti Malaysia Terengganu. Her recent research work focuses on improving organizational decision-making practices using technologies. This includes research interest in the design, development, and evaluation of decision support systems for analyzing and improving decision processes. Her research interest also focusses on the areas of computer science, intelligent decision support systems, clinical decision support system, and information system as well as action research in education. She has presented and published over two hundred of research papers on the decision support system at various international and local refereed journals, conferences, seminars, and symposiums. She can be contacted at email: maizura@umt.edu.my. 


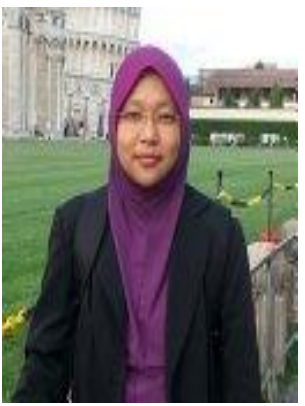

Rosmayati Mohemad (iD $8 \mathrm{SC}$ P is currently an associate professor at Faculty of Ocean Engineering Technology and Informatics, Universiti Malaysia Terengganu. She received her $\mathrm{PhD}$ degree in Computer Science from National University of Malaysia in 2013. Her research interest is in information system and knowledge engineering, specialized in decision support system and ontology modelling. This also includes research contributions in the design, development, and evaluation of intelligent decision support system for analyzing and improving decision-making process in various domain such as tender management, forensics, crime investigation and education. She is an editor of books, conference proceedings and reviewer of international journal and established conferences. She is a member of Malaysia Board of Technologists. She can be contacted at email: rosmayati@umt.edu.my.

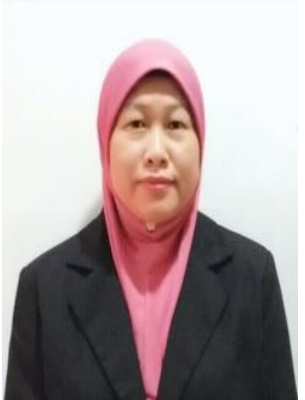

Zuriana Abu Bakar (D) SC SC is currently a senior lecturer at Faculty of Ocean Engineering Technology and Informatics, Universiti Malaysia Terengganu (UMT). She obtained her PhD from The University of Queensland (UQ), Australia in 2014. Her area of expertise is in Human Computer Interaction (HCI), particularly in interaction design and affective computing. Her research interest is focus on forensic computing, decision support systems, data mining and information systems as well. She has presented and published research papers on HCI, computer forensic, decision support systems, data mining and information systems in various international and local refereed journals (including Scopus and non-indexed), conferences, seminars, and symposiums. She can be contacted at email: zuriana@umt.edu.my. 